\title{
Assessment \& Evaluation of the Outcome for Closed and Open Method in Treatment of Segmental Tibial Fracture
}

\author{
Dr.JamalKadhimShwayel AL-Saeedi, \\ Lecturer,College Of Medicine University Of Thi-Qar
}

\begin{abstract}
Segmental tibial fractures are considered to be a special type of injury associated with high complication rates and are defined by the presence of two or more distinct fracture lines with completely isolating an intermediary segment i.e interruption of bone integrity at two levels(majority) or moreand are usually caused by a high-energy direct trauma with important soft tissue damage effect the both intramedullary and periosteal vascularization, which are predisposed to slow healing with creation of unsuitable biological conditions for fracture union. The aim of our study was to evaluate and assess the outcome of our policy on dealing with closed segmental fracture of the tibia treated by (closed or open) application of external tubular device fixator (AO group of ASIF). Within the period between October 1, 1998 and September 30, 2010 in Al Nasiriya military hospital, AL Amara military hospital and Al Husain teaching hospital, we collect 38 patients with displaced and minimally displaced closed segmental tibial fractures. We exclude the multiply injured patients died after surgical treatment in the course of further management, open fractures, and all the patients lost for follow up.

The minimally or undisplaced fractures were treated by closed application of the external device, while those with significantly displaced fractures, firstly managed by calcaneal continuous traction for a few days as an attempt for reduction, some of them were reduced to minimally displaced or acceptable position which were treated also by closed method, and some are remain significantly displaced, treated by open reposition and external fixation with the help of $X$-ray control for all cases. A range of motion exercise of ankle and knee joints post operatively were encouraged.

The mean age was 38.81 years. We collect and study 38 closed segmental tibial fractures i.e. (two fractures focuses for one bone), so we are dealing with 76 fractures in 38 patients. All the patients were treated by $A O$ unilateral external fixator arranged in multiplanartechnique for more rigid fixation and regarded as a definitive procedure for holding the fractures until clinical\& radiological union.Once a considerable callus seen, a loosening of the distal clamps and a very graduated weight bearing started, with the help of the crutches to permit an axial compression on the fractures sites until a secure union of the bone. Then the external fixation was removed and a partial weight bearing was continued with the help of the crutches until consolidation.

Healing of the bone occurred in 52 fracture focuses (68.42\%) patients, and 24 fractures (31.57\%) patients reported significant complications in the course of treatment that required further surgical management, 18 of them delayed union (23.68\%) patients and 6 of the fracture focuses(7.89)patients go to nonunion. The delayed union treated simply by dianamyzation with chips bone graft and sometimes rearrangement of the external fixator particularly the loose pines, all of them healed completely, while the nonunited were treated by (Revision procedure):- (revision of the external fixator with wider pins and extensive refreshment of the fracture ends and added a considerable amount of bone graft), so all of them were united successfully. We conclude that the external fixation is a suitable method for the treatment of segmental tibial fractures with an acceptable rate of complications.
\end{abstract}

\section{INTRODUCTION}

A segmental fracture is defined as a fracture with two or more fracture lines with one or more cylindrical intercalary segment(s). The majority of segmental tibial fractures have one intercalary segment (two fracture lines). These fractures are rare, according to the literatures, the frequency of segmental tibial fractures ranges from (1-6\%) ${ }^{(4)}$ and accounting for only up to about $12.8 \%$ of tibial fractures ${ }^{(9)}$. The goal of our study was to evaluate the clinical outcomes of tibial segmental fractures treated by external fixation( closed \& open) techniques, and we was assessing our experience and protocols for dealing with such problematic cases according to the available facilities in our circumstances and analyzing the problems and complications and how to resolved them. Segmental fractures are usually caused by high-energy trauma; motor vehicle and motorcycle crashes, falls from a height, industrial injures ${ }^{(25,45)}$. In the traffic accidents, are usually due to the effect of direct violent forces in which that a car, moving at high speeds, hits a pedestrian with a bumper into the lower leg.This injury is rarely isolated ${ }^{(16)}$, and associated with severe soft tissue damage of the lower extremity and accompanying injury ${ }^{(9)}$. 
This kind of damage creates unsuitable biological conditions for fracture healing, and because of the damage for both intramedullary and periosteal vascularization, segmental fractures are predisposed to slow healing and development of union complications (delayedunion, nonunion and pseudoarthrosis) ${ }^{(9)}$. However, there is no reliable scientific data to suggest that the presence of fractures at two different levels of the tibia necessarily compromises osteogenesis. The mechanism of healing of the two fractures is independent from each other. When the fractures are treated by means of rigid fixation with a plate or external fixator the medullary blood supply is rapidly restored, but peripheral callus does not form ${ }^{(24,25,41,40)}$. The treatment of segmental tibia fractures is demanding and time consuming, in which case a choice has to be made from different stabilization techniques, each with its own limits and morbidity ${ }^{(26,21,12,1,15,33)}$. The end result is oftenmediocre ${ }^{(20,30)}$.

\section{PATIENTS AND METHODS}

Within the period between October 1, 1998 and September 30, 2010 in Al Nasiriya military hospital, AL Amara military hospital and Al Husain teaching hospital, we collect 38 patients of closed segmental tibial fractures with different configurations (undisplaced, minimally or acceptable displacement and significantly displaced). We exclude the multiply injured patients died after surgical treatment in the course of further management, open fractures, and all the patients lost for follow up. The undisplaced and the acceptable displaced were treated by closed application of the external fixation, while those with significant displacement, firstly managed by calcaneal traction for a few days, some of them have been reduced to minimally or acceptable displacement : the apposition neednot be complete but the alignment must be nearperfect and no more than 7 degrees of angulation but the rotation should be absolutely perfect, and those also have been treated by closed application of the external fixation. While those which were remain significantly displaced, treated by open reduction, and in order to prevent further damage of intramedullary and periosteal bone vascularization, which is important for fracture healing, we had used a minimally access approaches (less invasive surgery as possible as we can): a two small incisions, one on each fracture focus with a small window just to reach the fracture ends for reduction and holding the reduction with the help of the X-ray control for repositioning of the fragments as anatomically as possible, then applied the fixator pins away from the fracture zones.Again the position of the fractures were checked during surgery by the X-ray control for both open \& closed method and sometimes with the help of the pins of the external fixator placed outside the fracture zone as joysticks with little manipulation; and any minor degree of angulation and incomplete apposition can still be corrected more.Displacement of the fibular fracture, unless it involves the ankle joint, is unimportant and can be ignored.A range of motion exercise of ankle and knee joints post operatively were encouraged. We collect and study the 38 case (two fractures focuses for one bone), (76) fractures in 38 patients. All the patients were treated by AO unilateral external fixator with each fracture segment was stabilized at least by two levels of fixation or more depend on the length of the segment and arranged in multiplanar technique to obtain more rigid fixation and regarded as a definitive procedure for holding the fractures until secure union.

The limb is elevated and the patient is kept under observation for 48-72 hours with broad spectrum antibiotic then discharge from the hospital and usually allowed up in the second or third day on the crutches with only touch-down weight bearing is allowed and followed at regular three- to four -weekly review and at physiotherapy sessions until a visible callus was appeared usually after 6 weeks, then loosen the distal clamps, and bearing a very minimal weight with the aid of crutches was allowed and gradually increasing the transfer of weight through the limb not the fixator to permit an axial compression on the fractures sites i.e. the frame will be converted to a dynamic configuration allowing the bone to bearweight. The weight bearing was progressed as callus develops. As further healing occurs until a secure union, this can be determined clinically and radiologically. The clinical union was achieved when the patient could bear weight fully through the affected leg without supporting aids or the fracture can be manually stressed, and this can be obtained by loosening the pinto-bar clamps and sliding the bar out through the clamps and on one side of the fracture, if very mild movement and or pain is detected, that means the fracture is still not securely united and so that the bar is replaced in its previous position.

Radiologically, the callus bridging across the fracture site on both the AP and the lateral projections was assessed. In well-reduced fractures with a barely visible gap, blurring of a fracture line was all that visible in some cases. When radiological and clinical union had been achieved, removal of the frames was carried out under a parenteral sedation\& analgesia in the clinic or rarely under general anesthesia. Sometimes when the patient seems to be non- cooperative, the limb is protected in a cast for few weeks. A graduated weight bearing ambulation was encouraged with crutches, and increased as the confidence and ability improved. A follow-up examination was every ( 3 - 4) weeks until consolidation. When full weight bearing is achieved without ambulatory aids, progressive strengthening exercises can be added. The vigorous activities usually are not 
allowed for approximately 6 months after fixator removal, and when the fracture site is strongly solid, and the pin sites have completely healed.

On the other hand If the amount of the callus has not increased over a 3-month period, so these are regarded as delayed union and further interventionneeded, such as chips bone grafting (usually taken from tibial tuberosity) which is necessary to promote healing, pins that become loose or grossly infected (persistent purulent drainage, radiographic lucency around pin) require removal and curettage and are replaced in a different sites if they are needed to maintain the stability. Oral antibiotics may be needed periodically to treat minor pin site infection. If there is still no visible radiological signs of healing or further callus formation again after three month, so these are regarded as nonunion and treated by Revision procedure:in which there was replacement of the external apparatus, we were using a more diameter schanizes(in order to obtained a more secure fixation and because of moderate disused osteoporosis) and arranged in multiplanar \& compression technique, a large amount of bone graft which was taken from iliac crest, extensive refreshment of the fractures site and removal of all fibrous tissue until the fracture ends bleed then incarcerate the big pieces of the graft in between the ends of the fracture segments. Sometimes and because of other injuries, some patients were unable to manage weight-bearing with crutches for several weeks.

The final follow-up examination was at least 1 year after surgery.

Healing of the bone occurred in 52 fractures (68.42\%) patients, and 24 fractures $(31.57 \%)$ patients reported significant complications in the course of treatment that required further surgical management, 18 fractures develop delayed union $(23.68 \%$ ) patients treated by dianamyzation, chips bone graft and replaced the loose or infected pines in a different site, and 6 fractures go to nonunion $(7.89 \%)$ patients which were treated by a (Revision procedure).

Collection of data was achieved by write down all the information of the cases, review of case notes, radiographs and clinical examination. The outcome measures were assessed: healing of the fracture, complicationsof treatment, functional recovery and general health status.

Healing was represented as time to union and the different fracture levels were also considered. Pin-site infection, which is common with the use of external fixators, was recorded, but listed as a complication only if secondary intervention other than the administration of antibiotics was needed. We was recording (4) cases $(10.5 \%)$. The care of pin sites was according to the recommendations of the Russian Ilizarov Scientific Centre for Restorative Traumatology and Orthopaedics (RISC RTO). This involves a weekly regimen of cleaning with alcoholic chlorhexidine and occlusion of the pin site by a bulky dressing. This protocol has previously been found to give a lower incidence of infection than daily cleaning with normal saline ${ }^{(7)}$.

Persistent drainage from a pin site, especially with loosening, should be treated by pin removal and curettage of the pin track and addition of a new pin at a different site, if necessary, for stability.

The functional recovery was recorded at the final review for the movement of the knee and ankle.

\section{RESULTS}

Between October1, 1998 and September 30, 2010, we collect 38 patients with closed segmental tibial fractures (two fracture focuses for one bone), so we are dealing with 76 fractures at different levels in 38 case, in order to evaluate and assess the final result of our protocol or policy on dealing withsuch problematic cases, and the prognosis or functional outcome of these fractures according to the available facilities in our hospitals at that time.In the analyzed group there were 32 male( $84.21 \%)$ and 6 female(15.78\%), The mean age was 38.81 years, ranging from 17years the youngest to 66years the oldest as mentioned in table(1) in this study.Having analyzed the side of injury, we found that the right side injury 26 cases $(68.42 \%)$ and the left side was 12 cases (31.57\%)table (2).By analyzing the etiological factors of injury, we found that different mechanisms were causing the closed segmental tibial fractures:a passenger in motor vehicles 15 patients $(39.47 \%)$, a pedestrians struck by motor vehicles 12 patients $(31.57 \%)$, a fall from a height 6 patient $(15.78 \%)$, a motor cycle accident 3 patients $(7.89 \%)$ and a direct blow by heavy things 2 patient $(5.26 \%)$ table (3). The segmental fractures means two fractures focuses in one bone at different levels so we have 38 tibias with 76 fractures: 22 metaphyseal and 54 diaphysial fractures in form of segments with different locations, table (5).Distal to proximal metaphysometaphyseal segment (DP. M-M) 2 cases $5.26 \%=4$ fractures 2 distal metaphysial which was united completely and 2 proximal metaphyseal also united.Proximal diaphyso-metaphyseal (P. D-M) 15 cases $39.47 \%=30$ fractures (15 proximal metaphyseal in which 11 of them united and 4 delayed which was united after treatment of delayed union, while the other 15 fractures of the same segment was located in the diaphysis in which 10 of them united and 5 develop union complication, a 3 was united after treatment and 2 develop nonunion which was treated by more comprehensive procedure and united completely. 
Diaphyso-diaphyseal segment (D-D)18 cases 47.36\% = 36 fracture located in the diaphysis in which 23 of them were united and 13 develop union complication also, a 9 of them was united after treatment and 4 develop nonunion which was also treated and united.Distal diaphyso-metaphyseal segment (D. D-M) 3 cases $7.89 \%=6$ fracture, a 3 in the metaphysis, 2 of them united and 1 was delayed which was treated and healed completely, the 3 diaphysial a 2 of them united and 1 was delayed and treated also, \{tables (4) \&(8)\}.

From 38 cases, there was14cases $(36.84 \%)$ undisplaced or minimally displaced which were treated by closed application of the external fixation.On the other hand a 24 cases $(63.15 \%)$ with displaced fractures were initially managed by calcaneal traction for few days, 8 cases $(33.33 \%)$ of the 24 displaced had been reduced to acceptable displacement and also treated by closed external fixation while the 16 cases( $66.66 \%$ of the 24 displaced remain in unacceptable position which were treated by open reduction and external fixation, and the help of the X-ray were used in all 38 cases(open \& closed) table(6).

By analyzing the fracture healing and the procedures used for treatment: 44 fractures treated closed (22patients), a 40 of them united completely (90.90\%), and 4 fracture $(9.09 \%)$ develop union complication.32 fractures treated open (16patients), a12 of them were united( $37.5 \%)$, while 20 fracture $\quad 43.75 \%$ ) also develop union complication, therefore the total 76 fractures (38 patients), a 52 fracture(68.42\%) were united completely on the other hand a 24 fracture(31.57\% ) develop union complication(delayed union \& nonunion) table(10).

Having analyzed the union complications and the anatomical site of the fractures, we found that: in 22(28.94\%) metaphyseal fractures, 17 (77.27\%) of them united and 5 (22.72\%) delayed union. In $54(71.05 \%)$ diaphysial fractures, $35(64.81 \%)$ united and $19(35.18 \%)$ of them develop union complication (13united+ 6nonunion), therefore an out of 76 fractures in a 38 patients with segmental tibial fractures, a $52(68.42 \%)$ united; while a $24(31.57 \%)$ develop union complications which also treated and unitedtable (9).Regarding union complication in our study, we found that a 24 fracture out of 76 develop union complication, in which 18 regarded as delayed union, and 6 non-union, all of them were treated and united completely, table (11).

In $4(10.5 \%)$ patients, the pin site infection was registered, and all of them were treated successfully, table (7).Secondary loss of reduction (redisplacement) was not occurred in our study.Callus and consolidation appeared earlier posterolaterally, both in the proximal and the distal fractures.Most of the 38 patients were returned to their previous activities with special modification for those associated with other major injuries.

Table (1): Distribution of patients by age and sex

\begin{tabular}{|c|c|c|c|c|c|c|c|}
\hline Age & $10-19$ yr & $20-29$ & $30-39$ & $40-49$ & $50-59$ & $60-69$ & Total \\
\hline Sex & $\%$ & $\%$ & $\%$ & $\mathrm{~N} \quad \%$ & $\mathrm{~N} \quad \%$ & $\mathrm{~N} \quad \%$ & $\mathrm{~N} \quad \%$ \\
\hline Male & 25.26 & $\begin{array}{ll}7 & 18.42\end{array}$ & $\begin{array}{ll}5 & 13.15\end{array}$ & 1026.31 & $\begin{array}{ll}6 & 15.78\end{array}$ & 5.26 & 3284.21 \\
\hline Female & $\begin{array}{ll}1 & 2.63\end{array}$ & 5.26 & 2.63 & $\begin{array}{ll}1 & 2.63\end{array}$ & $\begin{array}{ll}1 & 2.63\end{array}$ & I & $\begin{array}{ll}6 & 15.78\end{array}$ \\
\hline Total & $\begin{array}{ll}3 & 7.89\end{array}$ & 23.68 & 15.78 & 1128.94 & $\begin{array}{ll}7 & 18.42\end{array}$ & 5.26 & 100 \\
\hline
\end{tabular}

Table (2): Sideof Injury

\begin{tabular}{|c|c|c|}
\hline Side of injury & No. of cases & Percentage \\
\hline Right & 26 & $68.42 \%$ \\
\hline Left & 12 & $31.57 \%$ \\
\hline
\end{tabular}


Table(3):Mechanism of injury

\begin{tabular}{|l|c|c|}
\hline \multicolumn{1}{|c|}{ Mech.of injury } & No. of cases & Percentage \\
\hline Passenger in motor vehicles & 15 & $39.47 \%$ \\
\hline Pedestrians struck by motor vehicles & 12 & $31.57 \%$ \\
\hline Fall from a height & 6 & $15.78 \%$ \\
\hline Motor cycle accident & 3 & $7.89 \%$ \\
\hline Direct blow by heavy things & 2 & $5.26 \%$ \\
\hline
\end{tabular}

Table(4):Site Of The Segment

\begin{tabular}{|l|c|l|}
\hline \multicolumn{1}{|c|}{ The segment } & NO. of cases & percentage \\
\hline distal-proximalmetaphyso-metaphyseal (DP. M-M) & 2 & $5.26 \%$ \\
\hline proximal diaphyso-metaphyseal(P. D-M) & 15 & $39.47 \%$ \\
\hline diaphyso-diaphyseal(D-D) & 18 & $47.36 \%$ \\
\hline distal diaphyso-metaphyseal(D. D-M) & 3 & $7.89 \%$ \\
\hline
\end{tabular}

Table(5):Site Of The Fractures

\begin{tabular}{|c|c|c|c|}
\hline No. of the cases & No. of the fractures & Metaphysial fractures & Diaphysial fractures \\
\hline 38 & 76 & 22 & 54 \\
\hline
\end{tabular}

Table(6):Fractures configuration and Method of treatment

\begin{tabular}{|c|l|c|c|}
\hline Fractures configaration & \multicolumn{1}{|c|}{ No.of cases } & Method of treatment & percentage \\
\hline Undisplaced or minimally dis. & \multicolumn{1}{|c|}{14} & Closed ext. fix. & $36.84 \%$ \\
\hline Displaced 24 & $\begin{array}{l}\text { Reduced by skeletal } \\
\text { Traction }\end{array}$ & Closed ext. fix. & \\
& $\begin{array}{l}\mid c \\
83.33 \%\end{array}$ & $63.15 \%$ \\
\cline { 2 - 4 } & $\begin{array}{l}\text { Remain displaced 16 } \\
66.66 \%\end{array}$ & Open ext. fix. & \\
\hline Total & \multicolumn{1}{|c|}{38} & Closed +open & $100 \%$ \\
\hline
\end{tabular}

Table(7):Pin tract infection

\begin{tabular}{|l|l|}
\hline No.of cases & percentage \\
\hline 4 & $10.5 \%$ \\
\hline
\end{tabular}

Table (8): Fractures healing with anatomical situation

\begin{tabular}{|c|c|c|c|c|c|}
\hline segments & $\begin{array}{l}\text { NO.of } \\
\text { cases }\end{array}$ & $\begin{array}{c}\text { No. of } \\
\text { fractures }\end{array}$ & $\begin{array}{l}\text { Dist.Metap } \\
\text { hysial } \\
\text { fractures }\end{array}$ & $\begin{array}{c}\text { Prox.Metaphysial } \\
\text { fractures }\end{array}$ & Diaphysalfrctures \\
\hline DP. M-M & 2 & 4 & 2-united & 2-united & - \\
\hline P. D-M & 15 & 30 & - & $\begin{array}{l}\text { 15frctures } \\
\text { 11-united } \\
\text { 4delay }\end{array}$ & $\begin{array}{c}\text { 15frctures } \\
\text { 10-united } \\
5 \text { delay(3united } 2 \text { nonunited) }\end{array}$ \\
\hline D-D & 18 & 36 & - & 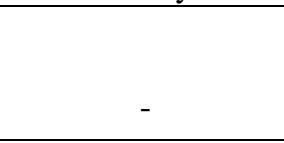 & $\begin{array}{c}\text { 36fractures } \\
\text { 23-Union 13Delay } \\
\text { (9united +4non) }\end{array}$ \\
\hline D. D-M & 3 & 6 & $\begin{array}{l}\text { 2-united } \\
\text { 1-delay }\end{array}$ & - & $\begin{array}{c}\text { 2-united } \\
\text { 1-delay } \\
\end{array}$ \\
\hline
\end{tabular}


Table(9):Union complications

DP. M-M :- distal-proximal metaphyso-metaphyseal

P. D-M :- proximal diaphyso-metaphyseal

D-D :-diaphyso-diaphyseal

D. D-M :- distal diaphyso-metaphyseal

Table(10):Fracture healing with method of treatment

\begin{tabular}{|c|c|c|c|c|}
\hline No.of the fractures\&patients & union & percentage & Delayed union & percentage \\
\hline $\begin{array}{c}\text { 44 fractures treated closed } \\
\text { (22patients) }\end{array}$ & 40 & $90.90 \%$ & 4 & $9.09 \%$ \\
\hline $\begin{array}{c}32 \text { fractures treated open } \\
\text { (16patients) }\end{array}$ & 12 & $37.5 \%$ & 20 & $43.75 \%$ \\
\hline $\begin{array}{c}\text { Total 76 fractures } \\
\text { (38 patients) }\end{array}$ & 52 & $68.42 \%$ & 24 & $31.57 \%$ \\
\hline
\end{tabular}

Table(11):Union, union complication\&method of treatment

\begin{tabular}{|c|c|c|l|}
\hline No. of fractures & union & Union complication & surgical management \\
\hline 76 & & & $\begin{array}{l}18 \text { delayed union treated by } \\
\text { dianamyzation, chips bone graft } \\
\text { and replaced the loose or infected } \\
\text { pines in a different site }\end{array}$ \\
\hline
\end{tabular}

\begin{tabular}{|c|c|c|c|c|c|c|}
\hline $\begin{array}{c}\text { Site of the } \\
\text { fracture }\end{array}$ & $\begin{array}{c}\text { No. of the } \\
\text { fracture }\end{array}$ & percentage & union & percentage & Union complications & $\begin{array}{c}\text { perc } \\
\text { enta } \\
\text { ge }\end{array}$ \\
\hline metaphyseal & 22 & $28.94 \%$ & 17 & $77.27 \%$ & 5 -delay & $22.72 \%$ \\
\hline diaphyseal & 54 & $71.05 \%$ & 35 & $64.81 \%$ & $\begin{array}{c}19 \text { delay(13united } \\
6 \text { 6nonunion) }\end{array}$ & $35.18 \%$ \\
\hline Total & 76 & $100 \%$ & 52 & $68.42 \%$ & 24 & $31.57 \%$ \\
\hline & & & & \multicolumn{2}{|c|}{$\begin{array}{l}6 \text { nonunion treated by revision } \\
\text { procedure with large amount of } \\
\text { bone graft. }\end{array}$} \\
\hline
\end{tabular}

\section{DISCUSSION}

Segmental tibial fractures are uncommon injuries . They are commonly caused by high-energy trauma. It is estimated that many of these fractures are open, and often part of multiple injuries. They are challenging to manage and have a significant complication rate, and because of the wide zone of injury, potentially reduced viability of the bone and problems with stabilization. These high-energy fractures are likely to be associated with injuries elsewhere. ${ }^{(9)}$

It is important to note that some of the segmental tibial fractures may require more than one surgery. The surgeon therefore, needs to plan ahead to make subsequent surgical interventions possible. There has been a significant change in the management of segmental tibial fractures. This has been made possible by the development of new orthopaedic implants. Various favored methods of treatment have been currently proposed including casting and functional bracing, internal fixation by plates and screws, intramedullary nailing and external fixations.

Nonoperative treatment of a segmental tibial fracture may need a long period of cast immobilization ${ }^{(35)}$, from our experience, we have added that the weight of a high thigh cast with involvement of a joint above and a joint below was a more disabling factor that not endeared by both the patient and the surgeon. 
Multilevel tibial fractures challenge the ability of standard implants to provide adequate stability at all levels. Fixation with plate and screws may achieve this, but it requires a large incision with stripping of the contused soft tissues, and this is an additional surgical injury to a compromised soft tissue envelope, with a substantial risk of skin necrosis and deep infection even with modern submuscular techniques. Muller et al. in the treatment of segmental tibial shaft fractures recommended a compression long plate that includes all three fragments. If the condition of the lower leg soft tissues is good, medially padded plate is recommended; while in case of compromised soft tissues of the lower leg and segmental tibial fractures, lateral plate placement is favored ${ }^{(27)}$.

In our study we used the external fixation that includes all three fragments easily (multilevel stability), in case of open reduction it requires a small incisions (minimally invasive technique), so not need too much periosteal stripping and less soft tissue trauma which is adversely effect on healing processes.

Conventional Kuntscher intramedullary nailing can neither give enough rotational stability nor correct the length of tibia. The use of reamed intramedullary nails and locking screws can be successful if the fracture segments are neither too proximal nor too distal. However, reaming incurs a biological cost which affects the blood supply to the tibial cortex ${ }^{(14)}$ Several reports in current orthopaedic literature have recommended intramedullary nailing of segmental tibial fractures with varying degrees of success $(3,6,11,13,16,19,22,44,45,46)$, but his method of fracture fixation, however, is not free of complications, among which chronic knee pain remains the most elusive one.Court-Brown et al reported an incidence of knee pain in $56.2 \%$ of patients, most of them significantly younger. There was considerable functional impairment with $91.7 \%$ of patients experiencing pain on kneeling and $33.7 \%$ having pain even at rest. They stated that $24.4 \%$ patients required removal of the nail ${ }^{(5)}$. Orfaly et al reported the need for nail removal because of knee pain in $80 \%$ of 61 patients, and after 16 months the pain had not resolved in $22(36 \%)$ of these patients. ${ }^{(29)}$ In a recent and most comprehensive review of the literature Katsouis et al., documented the high incidence of complications associated with intramedullary nailing of tibial fractures ${ }^{(17)}$. Muller et al. also indicate that the interlocking nail, possibly in combination with a narrow plate on the edge of the tibia, is a good solution in the treatment of segmental fractures. The authors do not suggest the reaming of the medullary canal as there is a danger that pieces of shaft fractures could be torn out of the soft tissues ${ }^{(27)}$. While in the our study the standard AO tubular external fixator give rise enough rotational stability and correct the length of tibia, when the fixator is successfully applied even the fracture segments are too proximal or too distal, and the fractures can be stabilized immediately, and early ambulation becomes possible without reaming of the medullary canal and so there is no danger of the fragment could be torn out of the soft tissues in addition to that, there was no chronic knee pain neither on kneeling nor at rest, and the fixator device not stay there for a long period, it was removed once there is radiological \& clinical union.

The final suitable option for us in the stabilization of these fractures is the external fixation. This method has the potential to leave a very small effect on the biology of the fracture and is probably equivalent to conservative methods if:- Fixation pins are kept away from the fracture zones. Closed application of the fixator as in those with undisplaced or minimally displaced segmental fractures.In open reduction we used a minimally access approaches (less invasive technique as possible as we can) as mentioned above.

Mitković et al mentioned that a possible explanation for some of the complications of the uniplanar stability provided by standard external fixators, but unilateral external fixator with convergent pins orientation provides necessary stability of the segmental fracture and support, which is important for fracture healing. Two pins of the external fixator fix proximal and distal tibial fragment, and one or two pins of the external fixator fix the intermediate fragment, depending on its size ${ }^{(25)}$.

In our policy\& protocol we had solved these problems successfully by try to produce multiplanar rigidity with multilevel stability on the use of the standard AO external fixation in which the application of the schanizes pins not only perpendicular but at a different angles (multiangles) with rotation of the clamps at the same directions of the pins therefore we obtained a multiplanar rigidity, while the multilevel stability can be obtained by increasing the number of the pins. Usually we used (2-4) pins for each segments according to the size, but not used one pin for a segment even a small size. Previous reports have documented its success for segmental tibial fractures, but have also stated problems with malunion, nonunion and deep infection ${ }^{(45,34)}$. In this study, and from the our accumulative experience, as mentioned above, the external fixation has the potential to provide multilevel stability with multiplanar rigidity of the fracture with minimal disruption of the soft-tissue, in addition to that we have no interlocking nail facilities, it was not provided at that time and we have no full experience on these procedures, therefore we were regarding the external fixation is the only method on dealing with such type of injuries in our circumstances. We had also stated problems in union (delayed union\& nonunion):- 
We have 76 fractures in 38 patients in which $52(68.42 \%)$ had been united and $24(31.57 \%)$ had union complications in which 18 of them delayed union \& a 6 of them non-union. The delayed union wastreated by dianamyzation, chips bone graft from tibial tuberosity and replaced the loose or infected pins at a different site, on the other hand the nonunion was treated by total revision procedure with extensive refreshment of the fracture ends and added a large fragments of bone graft taken from iliac crest.

In general, the treatment of segmental tibial fractures can be non-operative and operative. ${ }^{(34,36)}$

But we are strongly emphasized on that the segmental fractures are rarely suitable for non-operative treatment, except for sometimes in undisplaced fractures and particularly a young patients, can be treated by above knee plaster cast, but still we are insist that these are a more disabling factors, a long period of casting with a heavy weight and not moving the joints above and below, and so all these are sometimes not favorite by the surgeon and the patient himself.

On the other hand, in case of displacement, and in order to achieve manual reposition, it is necessary to provide stability of both fracture focuses by performing manual maneuvers, it can be accomplished in a single focal point of fracture, and while trying to perform the reposition of the second, a displacement usually occurs in the previous one. Maneuvers are repeated several times, thus damaging more soft tissues of the leg. And if a satisfactory repositioning of the fragment under X-rays is achieved and plaster immobilization is applied, a secondary displacement of the fragments usually occurs as soon as the edema at the fracture site subsides in addition to that, on application of the cast, will included a joints and also the weight of the cast will induced more disability than the frame of the external fixation which is lighter and can moving the joint above and the joint below. For these reasons, the majority of segmental tibial shaft fractures require surgical treatment.

Unreamed nails have been proposed as a compromise, and the achievement of multilevel stability can be difficult ${ }^{(16)}$ Very short proximal segments are notoriously difficult to control, even with modern intramedullary nails and alterations to the technique of insertion have to be used to avoid malalignment. ${ }^{(43)}$

In a retrospective assessment, Giotakis N. et al. present their treatment of 20 patients with segmental tibial fractures, who were treated between 2000 and in 2006 with circular external fixator. In 18 patients there was fracture healing, whereas in 2 patients the nonunion and pseudoarthrosis formation were reported. In one patient, the treatment was continued with circular external fixator, and in other one with open and autologous bone grafting. In one patient, osteomyelitis developed around the wire, so that the replacement and debridement were performed. In three patients, fracture healed with angular deformity, and also they emphasized that the circular external fixation to be a reasonable method of treatment, which leaves a small biological 'footprint' and can achieve multilevel stability. There is a good time to union, a low rate of re-operations and good functional and general health-status ${ }^{(10)}$.

From assessment of our study in which a segmental tibial fractures were treated by unilateral frame of the AO tubular external fixation, it was also leaves a small biological 'footprint', and a good time to union, a low rate of re-operations and good functional and general health-status outcome and can achieve multilevel stability with multiplanar rigidity even when very short proximal segments, particularly when the pins are arranged in multiangles and multi directional technique.

In our study a ( 76 ) fracture in 38 patient in which a 44 fractures (22patients) treated closed, 40 (90.90\%) united early and 4 fracture delayed union treated by simple procedure and united successfully, while a 32 fractures (16patients) treated by open reduction, 12 fracture $(37.5 \%)$ united early and 14 fracture delayed union also treated by simple procedure and united successfully, a 6 fractures developed nonunion which was treated by more comprehensive procedure and was united completely.

Pin tract infection was developed in 4 cases $(10.5 \%)$ which was treated and cured without reluctance.

We have no registration of any full blown pseudoarthrosis and the all fractures healed without any significant angular deformity unless with $\leq 7$ degrees of angulation can be considered to be clinically and cosmetically good results, since such deviations from the normal are not complications. They are aesthetically difficult to recognize with the naked eye, do not produce a limp, or are likely to produce late osteoarthritic changes ${ }^{(23)}$.

V.

\section{CONCLUSIONS}

1. We emphasized on that the multilevel fractures are considered to be a special type of injury associated with high complication rates and are usually caused by a high-energy direct trauma.

2. We strongly believed that the segmental fractures are a difficult group to manage besides severe open fractures ${ }^{(9)}$.

3. These fractures are rarely encountered, and are an infrequent occurring injury in our region as stated by others literatures also ${ }^{(4,9)}$. 
4. We have also found that callus formation and consolidation was observed earlier in the posterior and lateral parts of the tibia, both in the proximal and the distal fractures. Our view is that supporting the fact (more muscular coverage, better vascular supply).

5. Healing at the metaphysis is faster and union complication less than in diaphysis.

6. Healing in closed method is better with less union complications than in open method.

7. Calcaneal traction with gradual increasing the weight, according to the progress of the reduction for a few days is a very important preliminary measure to produce gradual correction as an attempt for closed reduction in significantly displaced fracture leg bones and also regarded as a provisional management when the skin viability is doubtful.

8. We regarded the AO tubular external fixators with their different constructs as a highly versatility apparatus that we can obtain multiplanar rigidity when the pins arranged in multiangles orientation and multilevel stability when the number of the pins increased.

9. From this retrospective assessment, we conclude that the external fixator apparatus must be considered as a reasonable method of treatment of the segmental tibial fractures with an acceptable rate of complications, a low rate of re-operations and good functional and general health-status outcome and there was no considerable functional impairment.

10. We conclude that the segmental fractures are better to be treated operatively rather than non-operative even minimally displaced.

11. Bone graft must be considered as prophylactic measures for open reduction and external fixation segmental tibial fractures.

12. They stated that an interlocking nail can offset the shortcomings of plating and conventional Kiintscher nailing $^{(8)} \quad$ we concluded that the external fixation can also offset the shortcomings of plating and conventional Kiintscher nailing and the fractures can be stabilized immediately, and early ambulation becomes possible.

13. The satisfactory results and the acceptable rate of union in our study support the general facts that stated by the authors : ( the closed or minimally invasive treatment of segmental fracture tibia and if allowed to experience physiological motion at the fracture site usually heal uneventfully and also the early introduction of the graduated weight bearing and the freedom of motion of all joints that the external fixation permits result in a very little motion at the fracture site, which in turn enhances osteogenesis $)^{(18,31,32,37,39,38,41,40,42)}$

14. We emphasized on that the management of these fractures in developedcountries poses a formidablechange to the treating surgeon, a number of available implants has escalateddramaticallyover the last decades and the treating surgeon is simply overwhelmed by these implants and the new concepts and surgical techniques that accompany them ${ }^{(28)}$. While in less developed countries these concepts more or less different, and therefore in our city we are concentrated on the most available osteosynthesis(the standard external fixation)with full experience on them and so this is very good lesson for the under developed countries on dealing with such problematic injuries.

15. Lastly we strongly agree with Ching-Kuei Huang et al, that there are no clear therapeutically- relevant guidelines regarding classification of segmental tibial fractures treatment approaches and evaluation of functional outcome using validated scales. These are the crucial issues or challenges facing future clinical research studies. Literature search retrieved very few articles ${ }^{(2)}$.

\section{REFERENCES}

[1]. Bonnevialle P, Cariven P, Bonnevialle N, et al (2003) Segmental tibia fractures: a critical retrospective analysis of 49 cases. Rev ChirOrthopAppar Mot 89: 423-432.

[2]. Ching-KueiHuang, Wei-Ming Chen, Tain - Hsiung Chen and Wai-Hee Lo. Segmental tibial fractures treated with interlocking nails. ActaOrthop. Scand. 1997; 68 (6): 563 - 566.

[3]. Coosemans, W., Rommedss, P., Broos, P., Gruwez, J.A.: Specific problems in the management of segmental fractures of the tibial shaft. ActaChir. Belg., 88:347-353, 1988.

[4]. Court-Brown CM, Mac Birnie J. The epidemiology of tibial fractures. J Bone Joint Surg(Br) 1995; 77: 417- 21.

[5]. Court-Brown, C. M., Gustilo, T., Shaw, A. D.: Knee pain after intramedullary nailing: its incidence, etiology, and outcome. J. Orthop. Trauma, 11:103-5, 1997.

[6]. Court-Brown, C. M., Will, E., Christie, J., Mcqueen, M. M.: Reamed or unreamed nailing for closed tibial fractures. A prospective study. J. Bone JtSurg 78-B:580-587, 1996.

[7]. Davies R, Holt N, Nayagam S. The care of pin sites with external fixation. J Bone Joint Surg [Br] 2005;87-B:716-19.

[8]. Ekeland A, Thoresen B 0, Alho A, Stromsoe K, Folleras G, Haukebo A. Interlocking intramedullary nailing in the treatment of tibial fractures-A report of 45 cases. ClinOrthop 1988; 231: 205-5.

[9]. Giannoudis, A.F. Hinsche, A. Cohen, D.A. MacDonald's, S.J. Matthews, R.M. Smith. Segmental tibial fractures: an assessment of procedures in 27 cases. Injury, Int. J. Care Injured. 2003; 34:756 - 762.

[10]. Giotakis N, Panchani S.K, narayan B, Larkin J.J, Maskari S. Al, Nayagam S. Segmental fractures of the tibia treated by circular external fixation. J Bone Joint Surg (Br) 2010; 92(5): 687-92.. 
[11]. Gregory, P., Sanders, R.: The treatment of closed, unstable tibial shaft fractures with unreamed interlocking nails. Clin. Orthop., 315:48-55, 1995.

[12]. Henley MB, Chapman JR, Agel J, et al (1998) Treatment of Type II, IIIA and IIIB open fractures of the tibial shaft: A prospective comparison of unreamed interlocking intramedullary nails and half-pin external fixators. J Orthop Trauma 12: 1-7

[13]. Hohaus, TH., Bula, F., Bonnaire, F.: Intramedullary osteosynthesis in the treatment of lower extremity fractures. ActaChir. orthop. Traum. čech., 75:52-60, 2008

[14]. Hupel TM, Aksenov SA, Schemitsch EH. Effect of limited and standard reaming on cortical bone blood flow and early strength of union following segmental fracture. J Orthop Trauma 1998;12:400-6..

[15]. Johner R, Staubli HU, Gunst M, et al (2000) The point of view of the clinician: a prospective study of the mechanism of accidents and the morphology of tibial and fibular shaft fractures. Injury 31:C45-49 Kakar S, Tornetta P 3rd. Segmental tibial fractures: a prospective evaluation. ClinOrthop 2007; 460: 196-207. PMid:17353796....

[16]. Katsouis, E., Court-Brown, C., Giannoudis, P.: Incidence and aetiology of anterior knee pain after intramedullary nailing of the femur and tibia. J. Bone Jt Surg., 88-B:576-580, 2007

[17]. Kenwright, J., Richardson, J. B., Goodship, A. E., Evans, M., Kelly, D. J., Spriggins, A. Newman, J. H., Burrough, S. J., Harris, J. D., Rowley, D. I.: Effect of Controlled Axial Micromovement on Healing of Tibial Fractures. Lancet, 2:1185, 1986.

[18]. Kuhn, M., Hansen, M., Rommens, M.: Extending the Indications of intramedullary nailing with the Expert Tibial nail. ActaChir. Orthop. Traum. čech., 75:77-87, 2008.

[19]. McGraw JM, Lim EV (1988) Treatment of open tibial-shaft fractures. External fixation and secondary intramedullary nailing. J Bone Joint Surg (Am) 70: 900-911

[20]. Melichar J, Horalek F, Novotny F, et al ( 2004) Conversion of an external fixation to that with an intramedullary pin in cases of complicated diaphyseal fractures. RozhlChir 83: 396-398

[21]. Melis, G. C., Sotgiu, F., Lepori, M., Guido, P.: Intramedullary nailing of segmental tibial fractures. J. Bone Jt Surg., 63-A:1310$1318,1981$.

[22]. Merchant, T. C., Dietz, F. R.: Long-term follow-up after fractures of the tibial and fibular shafts. J. Bone Jt Surg., 71- A:599606, 1989. In: Orfaly, R., Keating, J. E., O’Brien, P. J.: Knee pain after tibial nailing: Does the entry point matter? J. Bone Jt Surg.,77-B:976-7, 1995.

[23]. Merianos, K. Papagiannakos, E. Scretas , P. Smyrnis. Ender nails for segmental tibial fracture. Early weight bearing in 22 cases. ActaOrthopScandanavia 1988; 59 (3) : 297-301.

[24]. Mitković M, Bumbasirević M, Golubović Z, Mićić I, Mladenović D, Milenković S, Lesić A, BumbasirevićV,Pavlović P, Karalejić S, Kuljanin G, Petković D. New concept in external fixation. ActaChirIugosl 2005; 52(2):107-

[25]. Mueller CA, Eingartner C, Schreitmueller E, et al (2005) Primary stability of various forms of osteosynthesis in the treatment of fractures of the proximal tibia. J Bone Joint Surg (Br) 87-B: 426-432

[26]. Muller ME, Allgover M, Schneider R. Manual of internal Fixation. 3rd edition, Springer Verlag, 1991

[27]. N. S. Motsitsi Chief Specialist / Head of Department.Dept. ofOrthopaedic Surgery., Kalafong Hospital Pretoria. Email: silas.motsitsi@up.ac.za. Fax : (012); 373 9031. Management of Segmental Tibial Fractures. East and Central African Journal of Surgery, Vol. 12, No. 2, November/December 2006, pp. 72-76.

[28]. Orfaly, R., Keating, J. F., O’brien, P. J.: Knee pain after tibial nailing. J. Orthop., Trauma, 11:10-3, 1997.17.

[29]. Ostermann PA, Knopp W, Josten C, et al (1993) Unreamed intramedullary nail or external fixator in complicated tibial fractures? A comparative analysis. Chirurg 64: 913-917

[30]. Park, Sang-Hyun, O'connor, K., Mckellop, H., Sarmiento, A.: The Influence of active Shear or Compressive Motion on Fracture Healing. J. Bone Jt Surg., 80-A, 868-878, 1998.

[31]. Perrin, S.: Evolution of the Internal fixation of long bones fractures. J. Bone Jt Surg., 84-B:1093-110, 2002.

[32]. Piper KJ, Won HY, Ellis AM (2005) Hybrid external fixation in complex tibial plateau and plafond fractures: an Australian audit of outcome. Injury 36: 178-184.

[33]. Rommens PM, Coosemans W, Broos PL. The difficult healing of segmental fractures of the tibial shaft. Arch Orthop Trauma Surg 1989; 108: 238-42

[34]. Sarmiento A, Gersten L M, Sobol P A, Shankwiler J A, Vangsness C T. Tibial shaft fracture treated with functional braces. J Bone Joint Surg (Br) 1989; 71: 602-9.

[35]. Sarmiento A, Latta LL. Functional treatment of closed segmental fractures of the tibia. ActaChirOrthopTraumatolCech 2008;75(5):325-31. PMid:190261859

[36]. Sarmiento, A., Latta, L. L.: Closed Functional Treatment of Fractures. Springer-Verlag 1981. 21.

[37]. Sarmiento, A., Latta, L. L.: Periosteal Fracture Callus Mechanics. AAOS Symposium on Trauma to the Leg and Its Sequella. Moore, T.M. (ed). The C.V. Mosby Company 1981, 175-186. 23.

[38]. Sarmiento, A., Latta, L. L.: The evolution of functional bracing of fractures. J. Bone Jt Surg., 88-B:141-148, 2006. 22.

[39]. Sarmiento, A., Mullis, D. L., Latta, L. L., Tarr, R. R., Alvarez, R.: A Quantitative Comparative Analysis of Fracture Bracing Under the Influence of Compression Plating versus ClosedWeight Bearing Treatment. Clin. Orthop., 149:232-239, 1980..

[40]. Sarmiento, A., Schaeffer, J. F., Beckerman, L., Latta, L. L., Enis, J. E.: Fracture Healing in Rat Femora as Affected by Functional Weight Bearing. J. Bone Jt Surg., 59-A: 369-375, 1977.

[41]. Toivanen, J. A., Vaisto, O., Kannus, P., Latvala, K., Honkonen, S. E., Jarvinen, M. J.: Anterior knee pain after intramedullary nailing of fractures of the tibial shaft. A prospective, randomized study comparing two different nail-insertion techniques. J. Bone Jt Surg., 84-A:580-5, 2002.

[42]. Tornetta P 3rd, Collins E. Semiextended position of intramedullary nailing of the proximal tibia. ClinOrthop 1996;328:185-9. 15 15 .

[43]. Wiss, D. A., Stetson, W. B.: Unstable fractures of the tibia treated with reamed intramedullary nails. Clin. Orthop., 315:56-63, 1995. 32 .

[44]. Woll T.S, Duwelius P.J. The segmental tibial fracture. Clinical Orthopaedics and Related Research. 1992; $281: 204$ - 207.

[45]. Zucman, J., Maurer, P.: Two level fractures of the tibia. Results in thirty six cases treated by blind nailing. J. Bone Jt Surg., 51 -B: $686-693,1969.34$ 